\title{
3-aminopropyltriethoxysilane functionalized nanoscale zero-valent iron for the removal of dyes from aqueous solution
}

\author{
Junying Zhang, Qingyang Liu, Yuanju Ding, Yiling Bei* \\ Key Laboratory of Special Functional Aggregated Materials, Ministry of Education,School of Chemistry and Chemical \\ Engineering, Shandong University, 250100, China \\ Corresponding author: e-mail: beiyiling@yahoo.com.cn
}

\begin{abstract}
Batch studies were conducted to investigate the potential of 3-aminopropyltriethoxysilane modified nano zero-valent iron (APS-NZVI) to adsorb two dyes (acid brilliant scarlet GR and reactive brilliant red K-2BP) from aqueous solution. APS-NZVI showed good adsorption performance for two dyes. Under the adsorption conditions of $\mathrm{pH} 4.5$, initial concentration was $100 \mathrm{mg} / \mathrm{L}$, and time $=4 \mathrm{~h}$, the maximum adsorption capacities of APS-NZVI were $121.06 \mathrm{mg} / \mathrm{g}$ for acid brilliant scarlet GR and $191.5 \mathrm{mg} / \mathrm{g}$ for reactive brilliant red $\mathrm{K}-2 \mathrm{BP}$, respectively. The results revealed that the adsorption behavior of the dyes on the nano-particles fitted well with the Langmuir model and the sorption kinetics fits well the pseudo-second-order rate equation.
\end{abstract}

Keywords: 3-aminopropyltriethoxysilane, nano zero-valent iron, acid brilliant scarlet GR, reactive brilliant red K-2BP, magnetic separation.

\section{INTRODUCTION}

With the increasing demands of textile products, printing and dyeing wastewaters have been largely produced, which becomes one of the main sources of severe pollution problems worldwide. Acid brilliant scarlet GR and reactive brilliant red K-2BP are the widely used dyeing reagents. The color produced by great amounts of organic dyes in water is of great concern because the color in water is aesthetically unpleasant ${ }^{1-2}$. Moreover, they are also the major sources of water pollution, which remain in waste effluents and undergo chemical changes, consuming dissolved oxygen. Therefore, the dyes may cause suspected carcinogenic and gene-toxic effects to human beings or mammals. However, due to the large degree of aromatic rings present in the dye molecules, the treatment of wastewaters via a biological process is difficult and ineffective, resulting in their being discharged into the environment ${ }^{3}$.

Among all wastewater treatments, the adsorption process has been recognized to be an effective and economical procedure for the removal of dyes from industrial effluents ${ }^{4-5}$. Magnetic separation has been one of the promising ways for an environmental purification technique because of producing no contaminants having the capability of treating a large amount of wastewater within a short time $e^{6-7}$. Several works on the use of magnetic nano-particles for removal, separation and determination of hazardous compounds and metals have been published ${ }^{8-12}$.

In our previous work, 3-aminopropyltriethoxysilane functionalized nanoscale zero-valent iron (APS-NZVI) was synthesized successfully and was applied to the adsorption of lead ions ${ }^{\mathbf{1 3}}$. In this work, APS-NZVI is utilized for the adsorption of acid brilliant scarlet GR and reactive brilliant red K-2BP from an aqueous solution. APS-NZVI has shown good adsorption performance for brilliant scarlet GR (Scheme 1) and reactive brilliant red K-2BP (Scheme 2). The sorption kinetics of the two dyes onto the APS-NZVI materials was investigated. The results revealed that the adsorption behavior of the dyes on the nano-particles fitted with the Langmuir model and the sorption kinetics fitted with the pseudo-second-order rate equation.

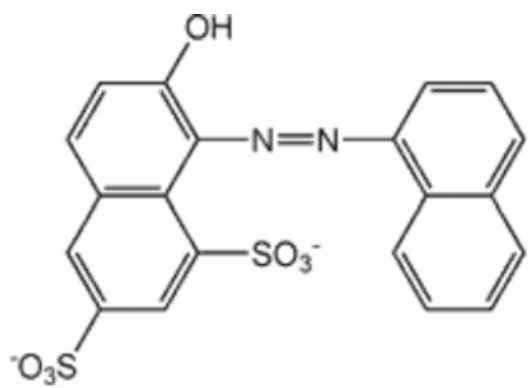

Scheme 1. Acid brilliant scarlet GR<smiles>O=S(=O)([O-])c1ccccc1N=Nc1c(S(=O)(=O)O[Na])cc2cc(S(=O)(=O)O)cc(Nc3nc(Cl)nc(Nc4ccccc4Cl)n3)c2c1O</smiles>

Scheme 2. Reactive brilliant red K-2BP

\section{MATERIALS AND METHODS}

\section{Materials and apparatus}

All chemicals were of analytical or reagent grade. Sodium borohydride ( $>85 \%$ ) was purchased from Sinopharm Chemical Reagent Co. (Shanghai, China). Ferric chloride $\left(\mathrm{FeCl}_{3} \cdot 6 \mathrm{H}_{2} \mathrm{O},>99 \%\right)$ was obtained from Tianjin Chemical Reagent Co. (Tianjin, China). Acid brilliant scarlet and reactive brilliant red K-2BP ( $>98 \%)$ were purchased from Beijing Chemical Reagent Co. (Beijing, China). Stock solutions of dyes were prepared by dissolving the powder in distilled water. Dye solutions of different initial concentrations were prepared by diluting the stock solution in appropriate proportions. All other reagents were of analytical reagent grade. De-ionized water was used through out this study. 
3-aminopropyltriethoxysilane (96\%) was purchased from Beijing Chemical Reagent Co. (Beijing, China) and used without further purification. The 3-aminopropyltriethoxysilane solution was prepared by dissolving the compound into ethanol/water (volume ratio is 2:1). The dyes were analyzed by direct measurement using the UV-visible spectrophotometer (Shanghai). The FTIR spectra of KBr pellets of APS-NZVI were obtained with a Nicolet Magna IR 750. Transmission electron miscrosopic (TEM) investigations were performed with $\mathrm{H}$-7500 instrument.

\section{Synthesis of 3-aminopropyltriethoxysilane (APS) modified nano-particles}

Based on the previous literature ${ }^{\mathbf{1 3}}$ and initial screening tests, the constituents of the micro-emulsion system were selected to prepare nano zero-valent iron. The solution was prepared as follows: $0.375 \mathrm{~g}$ cetyltrimethylammonium bromide (CTAB) as surfactant and $0.125 \mathrm{~g}$ 1-butanol as the co-surfactant were added into a $1.625 \mathrm{~g}$ n-octane solution. Then $0.375 \mathrm{~g}$ of $0.2 \mathrm{M} \mathrm{FeCl}_{3} \cdot 6 \mathrm{H}_{2} \mathrm{O}$ solution was added to the above mixture. The stirring rate was kept $3500 \mathrm{rpm}$ at 15 minutes, a transparent yellow solution was obtained and $0.46 \mathrm{~g} \mathrm{NaBH}_{4}$ solid was added into this solution. The reduction reaction made the solution turbid with gas production. After the gas evolution, the mixtures were stirred for another $30 \mathrm{~min}$ and then centrifuged at $5000 \mathrm{rpm}$ for $15 \mathrm{~min}$ to separate the black particles. The precipitates were first washed with a mixture of methanol and chloroform (volume ratio is 1:1), followed by ethanol. The nano-particles were separated using a magnet. The entire operation was performed under a nitrogen atmosphere. After this,approximately $50 \mathrm{~g} / \mathrm{L}$ 3-aminopropyltriethoxysilane was added drop wise into the solution for $90 \mathrm{~min}$. The solution was filter to separate the black particles. The route of synthesis is illustrated in Fig. 1.

\section{Batch adsorption experiments}

Adsorption tests were performed by a batch technique at $30^{\circ} \mathrm{C}$. Appropriately $0.02 \mathrm{~g}$ adsorbent was placed in a 50 $\mathrm{mL}$ flask of a dye solution containing acid brilliant scarlet GR and reactive brilliant red K-2BP (100 mg/L). The resulting mixture was mixed continuously for $4 \mathrm{~h}$ to reach equilibrium. The suspension was separated using a magnet and the concentration of brilliant scarlet GR and reactive brilliant red $\mathrm{K}-2 \mathrm{BP}$ in solution was determined by a UV-visible spectrophotometer set at $475 \mathrm{~nm}$ and 526 $\mathrm{nm}$, respectively.

\section{RESULTS AND DISCUSSION}

\section{Characterization of APS-NZVI}

3-aminopropyltriethoxysilane was successfully reacted with $\mathrm{OH}$ groups on the surface of nano valent iron. The infrared spectroscopic analysis of the APS-NZVI was shown in Fig. 2b. In the comparison with Fig. $2 \mathrm{a},-\mathrm{NH}_{2}$



Figure 1. Illustration of the chemistry involved in the synthesis of APS-NZVI ( $\mathrm{a}$ - hydrolysis, b - dehydration)

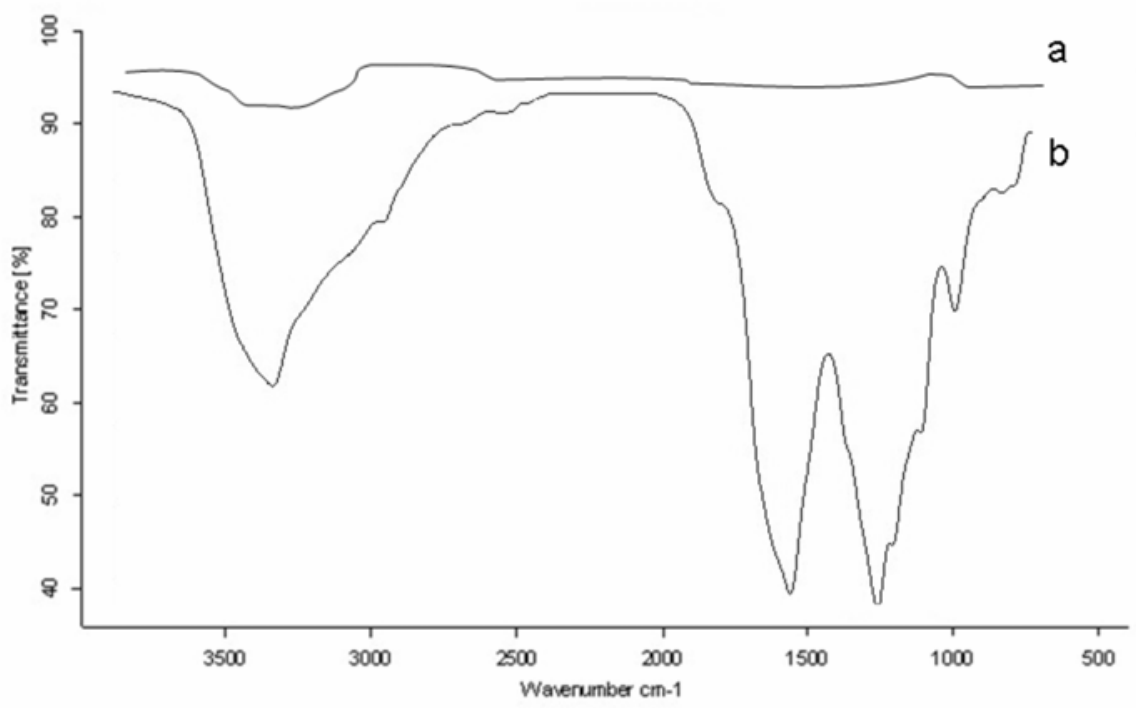

Figure 2. The FTIR spectra of the NZVI (a) and APS-NZVI (b) 
stretches were indicated at $3400 \mathrm{~cm}^{-1}$, and -Si-O-Si-stretches were located at $1000 \sim 1100 \mathrm{~cm}^{-1}$, which were typical absorption peaks assigned to APS. Figure 3 illustrates the TEM images of NZVI and APS-NZVI. As shown in Fig. $3 \mathrm{c}$ and $3 \mathrm{~d}$, the average diameters of NZVI and APS-NZVI were $36.4 \pm 18.4 \mathrm{~nm}$ and $53.2 \pm 20.6 \mathrm{~nm}$.

\section{Effect of pH variation}

The adsorption amount $[\mathrm{Q}(\mathrm{mg} / \mathrm{g})]$ was calculated as following:

$$
\mathrm{Q}=\mathrm{V}\left(\mathrm{C}_{0}-\mathrm{Ce}\right) / \mathrm{W}
$$

Where $\mathrm{W}$ is the weight of APS-NZVI $(\mathrm{g}), \mathrm{V}$ is the volume of the solution (L), and $\mathrm{C}_{0}$ and $\mathrm{C}_{\mathrm{e}}$ are the concentrations $(\mathrm{mg} / \mathrm{L})$ of acid brilliant scarlet GR and reactive brilliant red K-2BP before and after adsorption, respectively.

The effect of $\mathrm{pH}$ on adsorption capacity of APS-NZVI was shown in Fig. 4. It was indicated that the adsorption capacity was dependent on $\mathrm{pH}$. Acidic condition was favorable for the sorption of the two dyes, but the change in adsorption capacity was not obvious when $\mathrm{pH}<5$. When $\mathrm{pH}$ value was below 3 , the APS-NZVI was completely decomposed in the solution. Conversely, when $\mathrm{pH}>5$, the adsorption capacity decreased quickly with an increase in the $\mathrm{pH}$ value. At the case condition, the adsorption capacity was very low, so it was not investigated here. Therefore, $\mathrm{pH} 4.5$ was used as the optimum $\mathrm{pH}$ in this work. This trend agreed with the results of other studies on the adsorption of dyes on magnetic powder MnO$\mathrm{Fe}_{2} \mathrm{O}_{3}$ composite ${ }^{14}$.

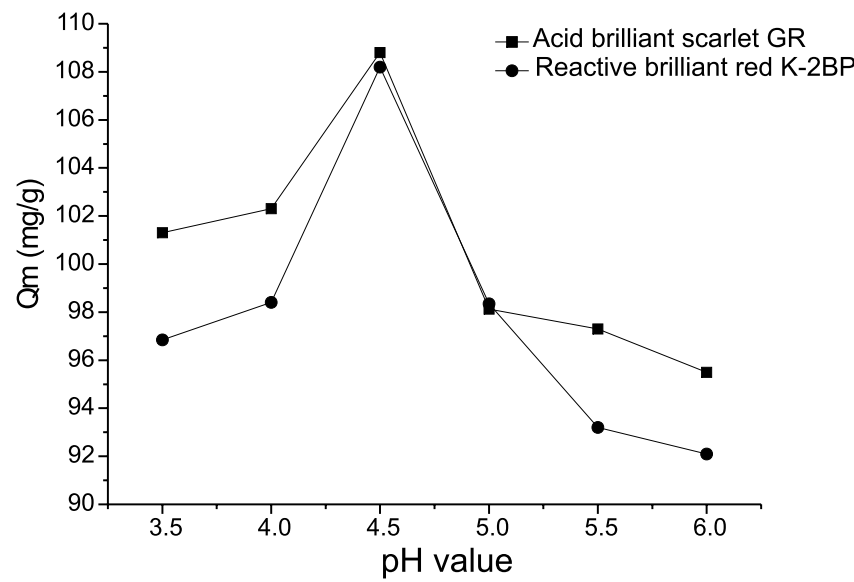

Figure 4. The effects of $\mathrm{pH}$ on adsorption capacity of acid brilliant scarlet GR and reactive brilliant red K-2BP. $\left(\mathrm{C}_{0}=50 \mathrm{mg} / \mathrm{L}\right.$, Time $=4 \mathrm{~h}$, Temperature $=30^{\circ} \mathrm{C}$ and APS-NZVI adsorbent was $0.02 \mathrm{~g}$ )

\section{Adsorption mechanism}

The function group of the ligand on the zero-valent iron surface was an $-\mathrm{NH}_{2}$ group under the condition of reaction. In view of the target dyes in solution, both dyes (acid brilliant scarlet GR and reactive brilliant red K-2BP) have an -OH group on the benzene ring. In retrospect to a previous report ${ }^{15},-\mathrm{NH} 2$ group normally reacts with $\mathrm{OH}$ group on the benzene ring to form the stable donor-



Figure 3. TEM images and electron micrographs histogram for NZVI nanoparticles(a, c), and APS-NVZI nanoparticles (b, d) 
acceptor bonds. Therefore, the APS-NZVI exhibited good performance on the adsorption of acid brilliant scarlet GR and reactive brilliant red K-2BP in aqueous solution. As shown in Fig. 5, the amount of two dyes adsorbed reached equilibrium at about $240 \mathrm{~min}$. The Langmuir isotherm and Freundlich isotherm equations adsorption were widely used in this study to calculate the adsorption parameters. The Langmuir isotherm theory assumes a monolayer coverage of adsorbing dye over a homogenous adsorbent surface. Once a dye molecule occupies a site, no further adsorption can take place at that site. The Freundlich equation is an exponential equation and therefore, assumes that as the adsorb dye concentration increases with the concentration of adsorbing dyes on the adsorbent surface. Table 1 listed the corresponding parameters and the correlation coefficient calculated by Langmuir and Freundlich isotherm equations. The Langmuir equation was found to fit well with the adsorption isotherms. The Langmuir equation was adopted in this study to calculate the kinetic data. In Langmuir equation, the adsorption kinetic rate was often calculated using the following equation: the pseudo-first-order adsorption kinetic equation (2) and the pseudo-second-order adsorption kinetic equation (3)

$$
\begin{aligned}
\frac{t}{Q_{t}} & =\frac{1}{k_{2} Q_{e}{ }^{2}}+\frac{t}{Q_{e}} \\
Q_{t} & =Q_{e}\left(1-e^{-k_{1} t}\right)
\end{aligned}
$$

Where $\mathrm{t}$ is the adsorption time; $\mathrm{k}_{1}$ and $\mathrm{k}_{2}$ are the pseudofirst-order adsorption rate constant and pseudo-secondorder adsorption rate constant, respectively; and Qt is the adsorption capacity at time $t$. As shown in Table 2, the results of the adsorption kinetics indicate that the adsorption rates of APS-NZVI for two dyes were very fast. The adsorption processes obeyed pseudo-second-order adsorption kinetics.

Table 1. Langmuir and Freundlich isotherm fitting param eters $\left(Q_{e}\right.$, adsorption capacity at equilibrium; $C_{e}$, concentration in the solution at equilibrium; $\mathrm{k}_{\mathrm{L}}, \mathrm{k}_{\mathrm{F}}$, $\mathrm{n}_{\mathrm{F}}$, adsorption equilibrium constants)

\begin{tabular}{|l|c|c|c|c|c|c|}
\hline \multirow{2}{*}{ Compound } & \multicolumn{3}{|c|}{ Langmuir model } & \multicolumn{3}{c|}{ Freundlich model } \\
\cline { 2 - 7 } & $\mathrm{Q}_{\mathrm{e}}$ & $\mathrm{K}_{\mathrm{L}}$ & $\mathrm{R}^{2}$ & $\mathrm{Ig} \mathrm{k}_{\mathrm{F}}$ & $\mathrm{n}_{\mathrm{F}}$ & $\mathrm{R}^{2}$ \\
\hline $\mathrm{GR}$ & 121.06 & 0.180 & 0.9911 & 1.077 & 2.025 & 0.9737 \\
\hline $\mathrm{K} 2-\mathrm{BP}$ & 191.50 & 0.055 & 0.9811 & 0.305 & 0.669 & 0.9594 \\
\hline
\end{tabular}

Table 2. Kinetic parameters and correlation coefficient of the dyes

\begin{tabular}{|l|c|c|c|c|c|c|}
\hline \multirow{2}{*}{ Compound } & \multicolumn{3}{|c|}{$\begin{array}{c}\text { Pseudo-first-order } \\
\text { equation }\end{array}$} & \multicolumn{3}{c|}{ Pseudo-second equation } \\
\cline { 2 - 7 } & $\mathrm{Q}_{\mathrm{e}}$ & $\mathrm{k}_{1}$ & $\mathrm{R}^{2}$ & $\mathrm{Q}_{\mathrm{e}}$ & $\mathrm{k}_{1}$ & $\mathrm{R}^{2}$ \\
\hline $\mathrm{GR}$ & 36.38 & 0.087 & 0.7710 & 43.48 & 0.064 & 0.9983 \\
\hline $\mathrm{K} 2-\mathrm{BP}$ & 120.10 & 0.036 & 0.9941 & 128.87 & 0.019 & 0.9997 \\
\hline
\end{tabular}

\section{CONCLUSIONS}

The adsorbent of APS-NZVI could be useful for the removal of two dyes (acid brilliant scarlet GR and reactive brilliant red K-2BP) from aqueous solutions. The maximum adsorption capacities for acid brilliant scarlet GR and reactive brilliant red K-2BP were up to $121.06 \mathrm{mg} / \mathrm{g}$ and $191.50 \mathrm{mg} / \mathrm{g}$ respectively. The function group of $-\mathrm{NH}_{2}$ on

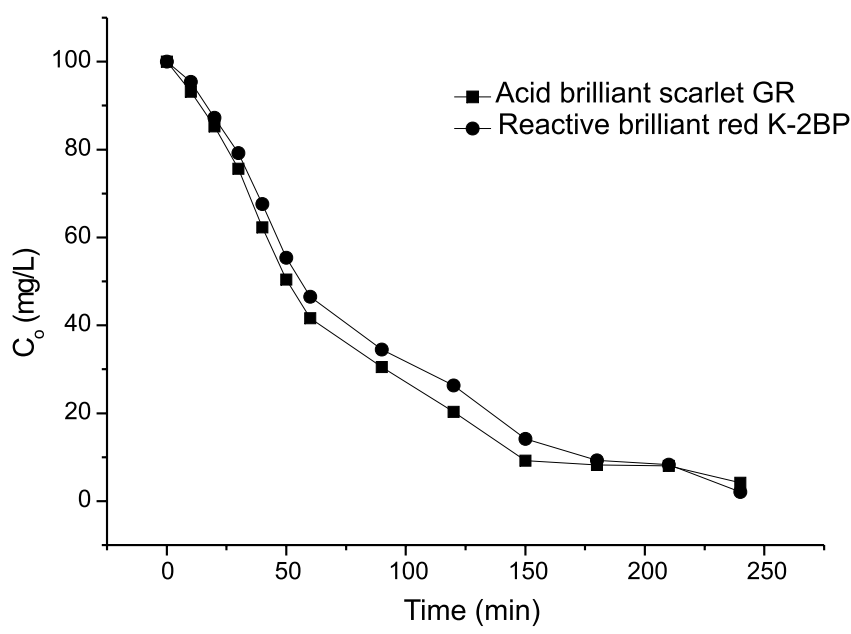

Figure 5. The effects of acid brilliant scarlet GR and reactive brilliant red $\mathrm{K}-2 \mathrm{BP}$ on adsorption equilibrium time. $\left(\mathrm{C}_{0}=100 \mathrm{mg} / \mathrm{L}\right.$, Time $=4 \mathrm{~h}$, Temperature $=30^{\circ} \mathrm{C}$ and APS-NZVI adsorbent was $0.02 \mathrm{~g}$ )

the zero-valent iron surface could react with -OH group on the target compound to form donor-acceptor bonds, which result in adsorption. The Langmuir equation was found to fit well with the adsorption isotherms. Moreover, the adsorption processes obeyed pseudo-second-order adsorption kinetics.

\section{LITERATURE CITED}

1. Nikos, M., Ouatfa, C. \& James, F. (2001). Kinetics of Soluble Chromium Removal from Contaminated Water by Zerovalent Iron Media: Corrosion Inhibition and Passive Oxide Effects. Environ. Sci. Technol. 35, 3948-3953. DOI: 10.1021/es001923x.

2. Wang, X.N., Zhu, N.W. \& Yin, B.K. (2008). Preparation of Sludge-Based Activated Carbon and Its Application in Dye Wastewater Treatment. J. Hazard. Mater. 153, 22-27. DOI:10.1016/j.jhazmat.2007.08.011.

3. Gong, J.L., Wang, B., Zeng, G.M. \& Yang, C.P. (2009). Removal of Cationic Dyes from Aqueous Solution using Magnetic Multi-Wall Carbon Nanotube Nanocomposite as Adsorbent. J. Hazard. Mater. 164, 1517-1522. DOI: 10.1016/ j.jhazmat.2008.09.072.

4. Yang, N., Zhu, S., Zhang, D. \& Xu, S. (2008). Synthesis and Properties of Magnetic $\mathrm{Fe}_{3} \mathrm{O}_{4}$-Activated Carbon Nanocomposite Particles for Dye Removal. Mater. Lett. 62, 645-647. DOI: 10.1016/j.matlet.2007.06.049.

5. Atia, A.A., Donia, A.M. \& Al-Amrani, W.A. (2009). Adsorption/Desorption Behavior of Acid Orange 10 on Magnetic Silica Modified with Amine Groups. Chem. Eng. J. 1, 55-62. DOI: 10.1016/j.cej.2008.12.004.

6. Rocher, V., Siaugue, J.M., Cabuil, V. \& Bee, A. (2008). Removal of Organic Dyes by Magnetic Alginate Beads. Water Res. 42, 1290-1298. DOI: 10.1016/j.watres.2007.09.024.

7. Kaminski, M.D., Nunez, L.,\& Visser, A.E. (1999). Evaluation of Extractant-Coated Ferromagnetic Microparticles for the Recovery of Hazardous Metals from Waste Solution. Sep. Sci. Technol. 34, 1103-1120. DOI: 10.1080/01496399908951083.

8. Geng, B., Jin, Z.H., Li, T.L., \& Qi, X.H. (2009). Preparation of Chitosan-Stabilized Fe0 Nanoparticles for Removal of Hexavalent Chromium in Water. Sci. Total. Environ. 407, 4994-5000. DOI: 10.1016/j.scitotenv.2009.05.051.

9. Zargar, B., Parham, H. \& Hatamie, A. (2009). Fast Removal and Recovery of Amaranth by Modified Iron Oxide Magnetic Nanoparticles. Chemosphere, 76, 554-557. DOI: 10.1016/j.chemosphere.2009.02.065. 
10. Krishnakumar, B., Majumdar, S. \& Manilal V.B. (2005). Treatment of sulphide containing wastewater with sulphur recovery in a novel reverse fluidized loop reactor (RFLR). Water. Res., 39, 639-647. DOI:10.1016/j.watres.2004.11.015.

11. Li, F., Vipulanandan, C. \& Mohanty, K.K. (2003). Microemulsion and Solution Approaches to Nanoparticle Iron Production for Degradation of Trichloroethylene. Colloid. Surf. A, 223, 103-112. DOI: 10.1016/S0927-7757(03)00187-0.

12. Allen, S.J., Gan, Q., Matthews, R. \& Johnson, P.A. (2003). Comparison of Optimised Isotherm Models for Basic Dye Adsorption by Kudzu. Bioresour. Technol. 88, 143-152. DOI: 10.1016/S0960-8524(02)00281-X.

13. Liu, Q.Y., Bei, Y.L. \& Zhou, F. (2009). Removal of Lead (II) from Aqueous Solution With Amino-Functionalized Nanoscale Zero-Valent Iron. Cent. Eur. J. Chem., 7, 79-82. DOI: 10.2478/s11532-008-0097-1.

14. Wu, R.C., Qua, J.H. \& Chen, Y.S. (2005) Magnetic powder $\mathrm{MnO}-\mathrm{Fe}_{2} \mathrm{O}_{3}$ composite-a novel material for the removal of azo-dye from water. Water. Res., 39, 630-638. DOI: 10.1016/j.watres.2004.11.005.

15. Manning, B.A., Kiser, J.R., Kwon, H. \& Kanel., S.R. (2007). Spectroscopic Investigation of Cr (III)-and Cr (VI)Treated Nanoscale Zerovalent Iron. Environ. Sci. Technol. 41, 586-592. DOI: 10.1021/es061721m. 